\title{
CONSTITUCIÓN, JUECES Y DEMOCRACIA. EL PARADIGMA FRANCÉS Y AMERICANO A PARTIR DE DOS REVOLUCIONES
}

\author{
Manuel Antonio Núñez
}

SUMARIO: Introducción. (I) EL MODELO JACOBINO. I 1 . Poder constituyente y Constitución como conceptos fundacionales de un nuevo orden. $\int$ 2. La Asamblea Nacional como garantía de la Constitución. $\int 3$. El legicentrismo como consecuencia de la primacía del Parlamento. a) Monopolio de la producción del Derecho. b) Omnipotencia del parlamento $e$ inexistencia del control judicial de la ley. $\int 4$. Antijudicialismo. (II) EL MODELO AMERICANO. $\int$ 1. Una parte del alma del constitucionalismo americano. $\int$ 2. Soberania y federalismo. $\int$ 3. Separación de poderes y democracia. \& 4. Judicialismo y judicial review. a) Judicialismo americano versus antijudicialismo europeo. b) Bases de la judicial reviem. $\int 5$. Constitución y Bill of Rights.

\section{INTRODUCCIÓN}

Según la conocida tesis de Harold Berman', toda la historia del derecho occidental se encuentra asociada con la idea de revolución, fenómeno del que por cierto no escapa el constitucionalismo moderno. En efecto, la idea racional del poder político fundado y limitado por el Derecho se nutre en gran parte (aunque, como se dirá, no de igual forma) de los principios forjados a partir de la Gloriosa Revolución británica (1688), de la Revolución Americana (1776) y de la Revolución Francesa (1789). No ha habido en la historia otras revoluciones a partir de las cuales la idea de un poder limitado ejerciera tanta influencía como en aquéllas.

Se ha dicho que uno de los principales rasgos de ruptura con el pasado fue la constitución escrita ${ }^{2}$, lo que permite separar la evolución del constitucionalismo en las colonias americanas y Francia, por una parte, y en las Islas Británicas por la otra. Como se sabe, el constitucionalismo como fenómeno y doctrina política (luego, en

\footnotetext{
Profesor de Derecho Constitucional, Universidad Católica del Norte y Universidad Católica de Valparaiso. Agradezco las criticas y observaciones hechas al borrador por Antonio C. Pereira Menaut (U, Santiago de Compostela) y Eduardo Aldunate Lizana (U. Católica de Valparaíso). Las traducciones que se reproducen en el texto, a menos que se indique otra cosa, son del autor.

'BERMAN, Harold: I as and Retolntion. The formation of the Westem I egal Trudition (Harvard University Press, Cambridge, Massachusetts / London, 1983).

2 MATEUCCI, Nicola: Lo Stato Modemo. Lession e peronsi (Il Mulino, Bologna, 1997), p. 134. El caso británico, desde luego, constituye un caso especial: al corresponder su desarrollo a fenómenos revolucionarios menos radicales y al haberse resistido a la idea codificadora promocionada en los Esstados Unidos, en Irancia y en la propia Inglatera (Bentham).
} 
el sentido formal-documental del término) nace paradójicamente en una nación ${ }^{3}$ que, hasta el día de hoy, se ha abstenido de concentrar el derecho constitucional en un documento solemne y escrito, y donde todavía es más que perceptible la idea de una Constitución tan presente en las fuentes no escritas como en las escritas ${ }^{4}$. No c bstante esta notable diferencia, como se verá más adelante, tras el modelo americano yace buena parte del pensamiento liberal anglosajón y del mos britannicus de concebir el Derecho, herencia de la cual los colonos no quisieron o no pudieron abjurar.

En las líneas que siguen se expondrán los modelos de constitución y democracia que se resultan a partir de las revoluciones americana y francesa, y cuyos postulados han resultado básicos para el desarrollo del derecho constitucional en occidente. Queda advertido que esta monografía no se orienta según el sentido sociológico profundo de la palabra revolución, para el cual sería discutible el carácter íntegramente revolucionario del fenómeno americano (que puesto en relación con los sucesos de Francia, podría presentarse como una simple guerra de independencia). El punto de vista que se adopta es menos extensivo y se restringe a la dimensión jurídico-constitucional, perspectiva en la cual sí es posible advertir el carácter revolucionario de ambos sucesos, bien frente al Antiguo Régimen, o bien frente a las formas que hasta esa época eran conocidas como instrumentos de reconocimiento y estructuración del poder político. Desde esta última perspectiva, y partiendo por aquello que se destacaba en el párrafo anterior, es indudable que ambos capítulos de la historia francesa y estadounidense, marcan un "antes" y un "después" en la historia del constitucionalismo.

El ejercicio de comparación que aquí se presenta no sólo refrescar la memoria sobre la historia de Europa y América del Norte sino también, a través de ello, recordar el contexto que observaron los padres de las primeras constituciones latinoamericanas. Las diversas visiones que emergieron tras ambas revoluciones, sea de la Constitución como -no sobra decirlo- del Derecho en general, están presentes en el pensamiento político y jurídico latinoamericano y, a pesar de los siglos, todavía definen el curso y lenguaje de nuestra política y de nuestras leyes fundamentales.

\footnotetext{
${ }^{3}$ Utilizo la voz nación en su sentido más amplio para no utilizar de Estado. En su sentido más estricto, el Reino Unido concentra no una sino cuatro naciones (cf. KEARNEY, Hugh: Las Islas Brilanicas. Historia de czatro naciones, Tr. J. Pardos, Cambridge University Press, Madrid, 1999), mientras que, por otra parte, como organización política aparece ajena a la noción de "Estado" (cf. PEREIRA, Antonio C.. El ejemplo onstitucionul de Inglaterna, Publicaciones Universidad Complutense de Madrid, Madrid, 1992, pp. 27-43).

$\Lambda$ pesar de carecer de una Constitución escrita, el acercamiento del Reino Unido al modelo continental es un proceso en curso. Al margen de los cambios de mentalidad, la pertenencia a la Unión Ėuropea, la adhesión al Convenio de Roma para la protección de los Derechos Humanos y las Libertades Fundamentales y la relativamente recienre : 'tuman Rights At (1998) han marcado decisivamente la evolución de la celebrada English Constitution.
} 


\section{I.- EL MODELO JACOBINO}

"Las voluntades particulares son sospechosas; pueden ser buenas o malas; pero la voluntad general es siempre buena; no ha engañado nunca, no engañará jamás".

Diderot, "Droit natuicl", Encyclopédie (1751-1765)

La teoría política y constitucional actual aplica el viejo adjetivo de "jacobinista" o "jacobino" para designar el paradigma de democracia y constitución que emerge tras la revolución de 1789, modelo que tendría decisiva influencia en el resto del continente europeo y también, tras las guer:as de independencia, en los pueblos iberoamericanos. Esta concepción -que ha sido recientemente resumida en tres palabras: estatismo, objetivismo y legicentrismo ${ }^{6}$ encuentra su fundamento filosófico en el iluminismo francés (y muy particularmente en la obra de Rousseau) que virtuosamente combinó sus aportaciones originales con el pensamiento liberal inglés que cien años antes había sostenido la Gloriosa Revolución.

A continuación se exponen cuatro rasgos relevantes del modelo jacobino.

\section{$\$ 1$. Poder constituyente y Constitución como conceptos fundacionales de un nuevo orden}

A diferencia de los anglosajones, los pensadores franceses se sintieron capaces de romper con el absolutismo e intentar construir sobre sus ruinas un orden enteramente nuevo que sirviera de modelo a la humanidad. Aunque la práctica demostraría la imposibilidad de este proyecto ${ }^{8}$, la teoría revolucionaria quiso fundar la organización política sobre una base nueva y original, y la noción que sirvió a este fin fue la de poder constituyente. El punto de partida de Emmanuel Sieyes, en su célebre ¿Qué es el Tercer Estado? , se fija precisamente en la falta de una

\footnotetext{
${ }^{5}$ En referencia al sector más radical de los revolucionarios franceses. Seguin se recuerda, las sociétés des amis de la Constitution se reunian en el Convento de los frailes dominicanos de San Jacobo, lugar de donde viene el nombre. Para las canacteristicas de esta versión de la democracia, vid. la voz "democrazia" en A. BARBER $\Lambda$ (a cura di): la basi filtsofiche del

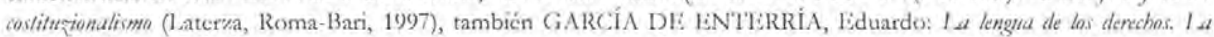
formación del Dercitio Priblico etaropeo Iras la retolución framosa (Alianza, $2^{3}$ reimpr. de la 1" ed. de 1994, Madrid, 2001), p. 78.

6 En contraste al pre-estatismo, subjetivismo y judicialismo propio de la concepción americana de los derechos, vid; ZAGRIBBELSKY, Gustavo: Le droit en dotacr. I/ diritto mite ( $\mathrm{I} r$. M. Leroy, Leonomica-PUAM, Aix en Provence-Paris,

7 Fieles a una constitución consuetudinaria, y del cual son magníficos exponentes en el siglo XVIII George SAVILE, el $2000)$, p. 57 , Marqués de Halifax (Political Thorghts and Reflections, 1750) y Edmund BURKE (Reflections on the Rerolution in France, 1790). Para ambes autores, la constitución no es algo que surge ex notv, lejos de surgir como acto de una voluntad y en un solo momento es algo que se hereda.

${ }^{8}$ Como lo evidencin GARCI supervivencia, continuidad y espectacular crecimiento de la burocracia servidora un dia del Rey, otro dia de la nación y otro dia del limperador.

1)

SIISYES, Limmanuel; Qu'est ce que le Tiers Etal?, 1789. Existe traducción al español ¿2ué es el Terrer Estado?. (M. Lorente y L. Vázquez), Alianza, Madrid, 1994. Este ensayo, que buena parte de la historiografía califiea peyorativamente como un
} 
Constitución: "Si no tenemos Constitución, hay que hacer una; sólo la nación tiene tal derecho"10 , puesto que "la nación existe ante todo, es el origen de todo" $"$ "El efecto jurídico-político de esta proposición se traduce en la concepción de la Constitución como un nuevo pacto originario de institución del poder, completamente opuesto al Derecho y a la tradición que habian servido de sustento a la monarquía precedente. De aquí resulta que los poderes que crea ese pacto derivan su legitimidad de aquél, son poderes constituidos, no pudiendo alterar los límites del poder que les ha sido confiado ${ }^{12}$ ni menos aún el contenido de las leyes fundamentales ${ }^{13}$.

El contraste con el pensamiento inglés lo advierte Maurizio Fioravanti al escribir que "con Dicey deviene más claro el significado más profundo de la célebre soberania del parlamento inglés. Aquella soberanía no tiene nada que ver con la primacia, política e institucional, de los representantes del pueblo soberano, que la revolución francesa había afirmado de varias maneras. Por el contrario, para un inglés como Blackstone, o como el mismo Dicey, afirmar que la soberanía de la más relevante institución política del propio país, o bien del Parlamento, significa propiamente negar que antes de él haya existido, como se pensaba en los tiempos de la revolución, no sólo en Francia sino también en los Estados Unidos, un pacto fundamental, un poder constituyente, que haya definido los contornos de todos los poderes, y en consecuencia también del parlamento mismo. El parlamento era en consecuencia proclamado soberano por los ingleses porque no debía su existencia a una ley constitucional de orden superior, querida por un poder a él precedente. Era soberano, en una palabra, porque no era representable como una autoridad derivada, legitimada del principio democrático de la soberanía popular"14.

\section{\$2. La Asamblea Nacional como garantía de la Constitución}

A partir de la Constitución de 1791, en Francia se instauró una balanza de poderes bastante desequilibrada e inclinada en favor de un parlamento que, por más que comulgara con la teoría de los poderes instituidos, resultó virtualmente omnipotente. Frente a la opción americana, esencialmente judicialista, el constitucionalismo francés prescindió de los tribunales en el reparto de los poderes

\footnotetext{
panfleto, ha tenido una enorme influencia en la teoria constitucional hasta nuestros dias. Vid. BOCKENFORDE, Ernst.

"F.l poder constituyente del pueblo. Un concepto limite del Derecho Constitucional", en Estudios sobre el Estado de Derecho y la Democracia (Tr. R. Agapito, Trotta, Barcelona, 2000), pp. 159 ss.

FIORAVANTI, Maurizio: Costituzione (II Mulino, Bologna), pp. 142-143. William BLACKSTONE (1723-1780) es autor de uno de los más celebradas descripciones del derecho inglés, los Commentaries on the Lans of England, en cuatro volúmenes (1765-1769). Albert VENN DICEY es conocido por ser el autor de uno de los más conocidos libros que, sobre la constitución británica, se hayan escrito durante el siglo XIX: Introdiction to the Study of the I anv of the Constitution (1885).
} 
constitucionales y optó por acotar el poder parlamentario a través de retóricos remedios "de papel" ", que posteriormente serían complementados por instrumentos políticos de defensa de la Constitución ${ }^{16}$.

Desde la teoría de la separación de poderes -modelada por Locke ${ }^{17}$ y consagrada por Montesquieu ${ }^{18}$ - el panorama que emergió tras la revolución se presentó como una "separación sin equilibrio"11. Por otra parte, desde la teoría de la soberanía, el parlamento apareció como doblemente soberano: (i) frente a las otras autoridades, en tanto representante de la nación, y (ii) frente a la nación, en tanto ésta no podía manifestar su voluntad sino a través de la Asamblea. ${ }^{20}$. Hay que recordar que de las dos visiones acerca de la representación (Rousseau versus Sieyes) fue la segunda la que primó, al aceptarse que la comunidad puede delegar el ejercicio de su voluntad en un cuerpo de delegados ${ }^{21}$, fenómeno que tuvo por consecuencia la "identificación sustancial entre voluntad general y voluntad de los representantes" 22 . En síntesis, esta tendencia constitucional "monística" llevó a la concentración de la representación del soberano en uno solo de los poderes constituidos ${ }^{23}$.

\footnotetext{
${ }^{15}$ Recuérdese el articulo $7 \mathrm{de} \mathrm{la} \mathrm{Déclaration} \mathrm{de} \mathrm{1789,} \mathrm{en} \mathrm{aquella} \mathrm{parte} \mathrm{que} \mathrm{decian} \mathrm{que} \mathrm{"los} \mathrm{que} \mathrm{soliciten,} \mathrm{expidan,} \mathrm{ejecuten} \mathrm{o}$ hagan ejceutar ördenes arbitrarias deben ser castigados". de la V República (1958) crea el Conscal Constitutionnel Sobre las características de este Consejo, vid.: BON, Pierre: "EI Conscil Constitutionnel francés y el modelo de Cortes Constitucionales europeas", en Revzita Chilena de Derecho, XX/2-3 (1993), T. I, pp.379-394; PARDO FALCON, Javier: El Constio Constitucional Francés (Centro de Estudios Constitucionales, Madrid, 1990), y RENOUX, Thierry: "El Consejo Constitucional y el Poder Judicial en Francin y en el modelo curopeo del control de constitucionalidad de las leyes", en Rerista Chilena de Derecho, XX/2-3 (1993), T, I, pp. $441-447$.

17

LOCKE, John: Scgundo tratado sobre el Gobierno Civil (The Second Treatise of Goternment. An essay concerning the trrie original, extent and end of citil gavemment, 1690), $\$ 143 \mathrm{y}$ ss. En lo sucesivo las citas corresponden a la ed. de P. Taslett, Two Treatives of Gotrmment (Stud. ed. de 1988, Cambridge University Press, reimpr. 2000).

${ }^{18}$ Es conocido que la identificación de distintas funciones al interior de la comunidad politica se remonta, aunque con fines meramente descriptivos, a Aristótcles (vid. Politica, especialmente $1279 \mathrm{~b}, 1289 \mathrm{~b}$ y 1329a). No obstante, la explicitación de dicha división como técnica para garantizar la libertad cívica, se encuentra cnunciada con la mayor claridad y popularidad en el cẻlebre lisbro Xl, Cap. VI del Espinits de las Leyes de (Ch. Montesquieu (1748).

19 BLANCO, Roberto: El valor de la Constitución. Separación de poderes, supremacia de la ley y control de constitucionalidad en los origenes del Istado liberal, Alianza, Madrid, 1998), p. 2.30.

20

Este fenómeno contrasta ciertamente con los dos órdenes de soberanía (o soberanía fraccionada) que, bajo la fórmula federalista, se articulan al otro lado del Atäntico. Cf. TOCQUEVIl.LE, La Democracia en Améria (1835-1840), Primera Parte, Cap. VIII, p. $158-160$ (ed. de J. P. Mayer, Tr. I. Cuéllar, Fondo de Cultura Económica, 2ª ed. castellana, 1957, reimpr. 1999)

${ }^{21}$ SIEYES, op. cit., pp. 143-144. Recuérdese que para Rousseau, en el Con/rało Socalal (1762) la soberania era indivisible (Libro I, Cap. II) y que la forma más perfecta de democracia era la directa (cap. IV). En lo sucesivo, las citas de esta última obra se harán desde la tr. de M. J, Villaverde (Teenos, Madrid, 1988).

22 BLANCO, Roberto: op. cit., p. 251.

23

FIORAV NNIT, Maurzio: Contiluzion, op. cit. 115.
} 


\section{\$3. El legicentrismo como consecuencia de la primacía del Parlamento}

\section{a) Monopolio de la producción del Derecho}

Una de las funciones que los parlamentos hasta hoy reclaman para sí es la función legislativa, esto es, la función de producir las normas generales y obligatorias rotuladas bajo el título de "leyes". Pues bien, este privilegio no se consolida a partir del modelo hritánico -que nace en una etapa de la historia en el que derecho era una cosa de "encontrar" antes que de "crear"- sino a partir del modelo francés. Y es que el proceso de monopolización de la producción del Derecho, generalizado a partir de la formación de los estados nacionales y del robustecimiento de las monarquías continentales, no pudo vaciarse en un caldo de cultivo mejor que aquel que resultó a partir de la revolución (para luego madurar bajo el centralismo del Imperio) ${ }^{24}$. Este proceso, que Max Weber describió como un proceso de expropiación de los poderes ${ }^{25}$, deriva en una suerte de nomocracia que todavía campea en Europa (aunque cada vez más devaluada frente a la llamada "crisis de la ley") y, especialmente, en América Latina (donde buena parte de los ciudadanos sigue pensando que la solución de la mayoría de sus problemas está en las leyes y en quienes las deben aprobarlas).

\section{b) Omnipotencia del parlamento e inexistencia del control judicial de la ley}

Pero este legicentrismo ${ }^{26}$ no se agota en este fenómeno de la monopolización. Hay otro rasgo todavía más relevante, cual es el descontrol jurídico de la ley como manifestación de las potestades normativas del parlamento. Mientras en Estados Unidos la judicial review aparece a menos de dos décadas de aprobada la Constitución, en Europa el model, jacobino influye decisivamente para que aquélla no aparezca sino acabada la primera gran guerra del siglo XX. En efecto, siendo la ley el continente natural de la virtualmente infalible voluntad general ${ }^{27}$ y admitiéndose como dogma de fe un principio de separación esencialmente

\footnotetext{
24

Ce. GLENDON, Mary, GORDON, Michael y CAROZZA, Paolo: Compuratite Legul Truditiont (2x ed., West Group, St. Paul, 1999), pp. 30 y ss. Como recordó Giovanni Tarello, a partir de la segunda mitad del s. XVIIl la codificación dejó de ser una exigencia técnica para convertirse en expresión de una politica para reformar el Derecho: Storia della Cultuna

25 WEBER, Max: La poltfica como vocación (1919, trad. de F. Rubio, Alianza, Madrid, 1998), p. 91. Gituridica Moderna. A.solutismo en codificazione del diritlo (Il Mulino, Bologna, 1976), p. 223.

26

"El legicentrismo es el punto sobn el cwal la neinhución media entre inditidualismo y estatalismo. En efecto, para los revolucionarios franceses y para la misma Declaración de derechos, la ley es algo más -y distinto- que un instrumento lécnico para garantizar mejor los derechos y libertades que ya se poseen. La ley es más bien un valor en sí y no un mero instrumento, porque sólo gracias a su autoridad se hacen posibles los derechos y las libertades de todos: con su ausencia, faltando un legislador firme y autorizado, se caería en el detestado pasado de la sociedad de los privilegios del antiguo régimen", FIORAVANTI, Maurizio: Los derechos fundamentales. Apuntes de historia de las constituciones (Tr. M. Martinez, 2" ed. 1998, Trotta, Madrid), p. 62 (cursivas en el original).

${ }^{27}$ ROUSSEAU, I.J : Contrato Social, op. cit., Libro I, Cap. III, pp. 28 y ss.
} 
antijudicialista (vid. infra $\$ 4$ ) el resultado no pudo ser otro, al menos originalmente, que la sustitución de un absolutismo por otro.

Esta suerte de omnipotencia del parlamento se explica por dos órdenes de razones. En primer lugar, y en severo contraste con el viejo parlamento inglés y el nuevo congreso americano, en la Asamblea Nacional no se dieron las condiciones para que fuerzas presentes en otra cámara permitieran alguna forma de control o de equilibrio. En segundo lugar, debe agregarse el ideario de la filosofía de moda: el Contrato Social de J. J. Rousseau. Si sólo en este tópico se compara el razonamiento de la ilustración francesa con la concepción de Thomas Hobbes, magnífico teórico del absolutismo, el resultado es sorprendente. Para Rousseau, a la sazón héroe de la democracia, la única forma convertirse en "amo de sí mismo" consistía en transitar hacia un estado civil $^{28}$ donde, al darse a todos sin darse a ninguno, ${ }^{29}$ gobernase una voluntad general que, bajo los resguardos necesarios, seria siempre recta e infalible ${ }^{30}$. Aunque, como es de todos sabido la fundamentación era distinta, la conclusión de Hobbes es idéntica: la ley, que no es consejo sino orden ${ }^{31}$, jamás podía ser injusta ${ }^{32}$. Paradójicamente sería aquella, y no ésta, la teoría que más lejos llevarian los radicales ${ }^{33}$.

Este fenómeno, condensado en la supremacía de la ley y en la defensa parlamentaria o política de la Constitución, viene a ser uno de los rasgos distintivos del valor de la constitución en la versión revolucionaria francesa ${ }^{34}$.

\section{\$4. Antijudicialismo}

En una visión que consideraba a la aristocracia judicial del Antiguo Régimen como un bastión más a demoler por la revolución, no es de extrañar que el modelo democtático que surgiera minusvalorara en extremo la función judicial. Esta concepción se resume en la idea del "poder nulo" y de la función judicial como

\footnotetext{
${ }^{28}$ ROUSSEAU: op, cit., Libro I, Cap. VIII, p. 20.

${ }^{29}$ ROUSSI:AU: op cit, tibro I, Cap. VI, p. 15.

${ }^{30}$ ROUSSEAU; op cit., Libro II, Cap. III, pp. 28-30.

HOBBES, Thomas: Leviathan. Or the matter, forme and power of a common-wealth ecclesiasticall and civil (1651): "that law in general, is not counsel, but command", Cap. XXVI \$137, p, 175. Utilizo la ed, de J. Gaskin, Oxford University Press, 1998.

32

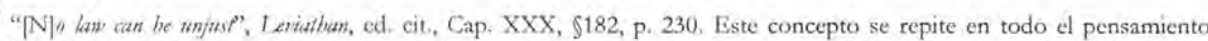
hobcssiano. Está presente en el De Gite (cuya versión inglesa data de 1642) y es repetida en A Dialogue between a Philosopher and a Student of the Common Lams an England (obra tardia de fecha incierta, pero que suele aproximarse hacia 1671).

33

Como recuerda Isaiah BERLIN, el poeta alemán Heine habia advertido cómo los conceptos filosóficos "engendrados un los despachos de un profesor puede destruir una civilización", describiendo a Rousscau como el arma ensangrentada que, en manos de Robespierre, habia destruide el Antiguo Régimen, Das conceplos de liberlad (Tr. de la ed. de 1969) por A. Rivero, Alianza, Madrid, 2001).

34

Vid, BLINCO, Roberto: op. at, p, 39
} 
"boca que pronuncia las palabras de la ley", conforme al más citado de los capítulos del Espíritu de las Leyes de Montesquieu ${ }^{35}$.

Si bien esta forma de entender la función de los jueces no puede desconectarse de las aberraciones propias de la judicatura del Antiguo Régimen, tampoco puede separarse del proceso que venía desarrollándose ya con el absolutismo y que arriba hemos explicado como la monopolización de la producción del Derecho. Ambos factores luego confluirán para abandonar el ideal de justicia universal propio del ius commune, y abonar el terreno para el positivismo que predominaría durante todo el siglo XIX y la primera mitad del siglo $\mathrm{XX}^{36}$.

En términos constitucionales de reparto de poderes, este antijudicialismo acarreó dos consecuencias importantes: (i) la total carencia de atribuciones, por parte de los jueces, para controlar la conformidad entre las leyes producidas por el parlamento y la Constitución y (ii) la plena y absoluta sumisión de los jueces a la ley. La primera lleva a confiar la defensa de la Constitución al propio parlamento, mientras que la segunda lleva a la articulación de una serie de artificios, especialmente procesales, para vigilar la estricta sujeción del juez a la ley. Entre estos últimos se encuentran el référé législatif, la casación, la obligación de motivar las sentencias, la creación de una jurisdicción especial para juzgar a los funcionarios de la Administración y un buen número de normas penales que castigaban la prevaricación.

El référé, creado por una ley en 1790 y recogido en la Constitución de 1791, obligaba al juez a consultar (literalmente "referir") al legislador el sentido de los textos legales obscuros o incompletos. La filosofía de este instrumento no era otra que reservar la interpretación y la creación de las leyes al parlamento, manteniendo la función judicial en la mera aplicación silogística de las mismas. Aunque este instituto no fue eliminado sino hasta 1837 , bajo el gobierno de Napoleón se redujo drásticamente su eficacia. De acuerdo al Code Civil de 1804 el juez que rehusase dictar sentencia a pretexto del silencio, oscuridad o insuficiencia de la ley sería perseguido como culpable del delito de denegación de justicia (art. $4^{\circ}$ ). Este nuevo artificio del influyente Código -que no hizo otra cosa que proscribir el recurso al non liquet-marcaría un paso importante en la evolución del civil law hacia la idea de un ordenamiento jurídico completo y sin lagunas ${ }^{37}$.

\footnotetext{
${ }^{35}$ MONTESQUIEU: Expinitu de las Leyes, XI, 6. No obstante en la ed. francesa se lee "bouche", en algunas traducciones castellanas esta palabra se traduce como "instrumento", asi la trad. de M. Blázquez (Tecnos, Madrid, 1985), p. 113. Una visión corregida de la concepción de Montesquieu, que suele resumirse y generalizarse en la frase citada, pucde consultarse en RAYNAUD, Philippe: "La loi et la jurisprudence, des lumières à la révolution française", en Archites de Philosophie do Druit 36 (1985), pp. 61-72

36

Vid. en este sentido PERELMAN, Chaim: La lógica jartdica y la nikta retórica (Tr. de la ed. de 1976, por L. Die\%-Pica\%o, Tccnos, Madrid, 1979), pp. $24 \mathrm{ss}$.

37

Sobre la tradición que consolida el Code, vid.: SCIUMÉ, Alberto: Principi genterali del diritto, Itincrari storici de wna formak (Giapipichelli, Torino, 1998), passim.
} 


\section{(II) EL MODELO AMERICANO}

"Esta comunidad está resuelta, como no lo duda ninguno de sus estados, a no conceder poderes no delegados, y consecuentemente ilimitados, a ningún hombre o asamblea de hombres sobre la tierra (...) El gobierno libre se funda en el recelo, y no en la confianza; es la desconfianza, y no la confianza, la que prescribe constituciones limitadas para obligar a aquellos a quienes estamos obligados a confiar el poder".

Jefferson, Resolution of Kentucky (Draft, 1798)

\section{\$1. Una parte del alma del constitucionalismo americano}

La cita de la Resolución de Kentucky resume parte de la esencia del paradigma norteamericano de constitución y democracia. En sus orígenes este modelo -que aportaría al mundo los conceptos de federalismo, presidencialismo y constitución escrita y rígida- se levanta sobre la base de la desconfianza o el recelo ${ }^{38}$ hacia el poder, encuéntrese éste en las manos de un hombre o de una asamblea de hombres. Una década antes Alexander Hamilton confesaba su visión pesimista del poder al decir que "si los hombres fueran ángeles, el gobierno no sería necesario" y que "si los ángeles gobernaran a los hombres tampoco serían necesarios los controles internos ni externos del gobierno" 3 .

Esta concepción -o sentimiento de jealousy hacia la concentración del poderse puede conectar sin dificultad con el liberalismo de Locke del siglo anterior: "está en situación mucho peor quien está expuesto al poder arbitrario de un hombre que tiene bajo su mando a 100.000 hombres que quien está expuesto al poder arbitrario de 100.000 hombre separados: nadie puede estar seguro que la voluntad de quien tiene tal poder es mejor que la de otros hombres, y sin embargo su fuerza es 100,000 veces más grande ${ }^{3+40}$. Como se verá más adelante este sentimiento, al que también se refiere Montesquieu ${ }^{41}$, adquiere en la experiencia norteamericana un rasgo de efectividad y estabilidad que no conoció el viejo continente durante el período inmediatamente posterior a la revolución francesa.

Pero el modelo americano no es sólo fruto de esta idea matriz. A ella hay que agregar otras ideas politicas y ciertas peculiaridades de la juvenil sociedad de colonos que separan este proceso de los acontecimientos del continente europeo.

\footnotetext{
38

"Jealousy" en el original. La autoria de la Resolución de Kentucky (y también de la de Virginia, de 1798), que no fue conocida sino dos décadas después, corresponde a J. Madison y T. Jefferson.

39

HAMILTON, Alexander: The Federalist Papers (1788), LI, p. 319-320. En lo sucesivo se cita la ed. de I. Kramnick (que a su ve\% reproduce la llamada J. \& A. Me Lean Fd. de 1788, Penguin Books, London, 1987).

"[E]s una experiencia eterna, que todo hombre que tiene poder siente la inclinación de abusar de él, yendo hasta donde encuentra limites. ¿Quién lo dirial La misma virtud necesita limites", L/Espiritu de las Leyer, op, cit, Libro XI, Cap. IV, p. 106.
} 
Entre estas últimas cabe llamar la atención sobre la relativa homogeneidad de la sociedad americana, con una creciente burguesía que influiría decisivamente en favor de la estabilidad del régimen post colonial, es "el gran aire de familia" a que se refería Alexis Tocqueville en La Democracia en América ${ }^{42}$.

En cuanto a las ideas políticas, la identidad americana se construye bien sobre el rechazo o bien sobre una reinterpretación de los conceptos políticos europeos. Ejemplo de lo primero es la prescindencia de un concepto tan caro para los estados nacionales europeos como la soberania; mientras que señal de lo segundo es la particular aplicación que se hace de la teoría de la separación de poderes de Montesquieu. Por su importancia, estas últimas ideas se van a explicar por separado.

\section{\$2. Soberanía y federalismo}

Para la teoría política europea la idea de soberanía resultó fundamental en la fundación de los estados nacionales y absolutistas. Según se sabe, la noción de un poder non superior recognoscens aparece en $\operatorname{Bodin}^{43}$ (y se consolida luego en Hobbes) para justificar el absolutismo $y$, como ningún otro concepto político afín a esa idea de poder, la idea es recogida por la revolución y vaciada en el parlamento para sobrevivir durante casi cuatro siglos en Europa. No obstante, a pesar de su notoria influencia en la Europa continental y después en las repúblicas latinoamericanas, el concepto no tuvo el mismo destino en Inglaterra ni en Estados Unidos. En el Reino Unido el concepto de parliamentary sovereignty explicó otra cosa: el poder del parlamento para frenar la monarquía y luego garantizar la paz y la unidad ${ }^{44}$. En los Estados Unidos, a su turno, se recogió la voz (sovereignty) o el concepto (authority of the state) mas en un entorno totalmente nuevo para lo que hasta entonces era la distribución territorial del poder: el federalismo.

Más aúr, como indica un autor, el modelo federal de Filadelfia supuso "un rechazo de un concepto cardinal de la filosofía política europea, el de la soberanía: en una estructura donde las competencias normativas deben ser repartidas entre los órganos de la federación y órganos de los estados individuales no puede encontrar

\footnotetext{
42

${ }^{2}$ Primera Parte, Cap. II, p. 55: "Todas las colonias inglesas tenian entre si, en la época de su nacimiento, un aire de gran familia. Todas, en un principio, parecian desrinadas a contribuir al desarrollo de la liberrad, no ya de la libertad aristocrática de su madre patria, sino de la libertad burguesa de la que la historia del mundo no presentaba todavia un modelo exacto".

43

Los Seis Libros de la República (1576)

${ }^{44}$ Cf. PEREIRA M., Antonio C: El cjemplo con.thitucional de Inglaterra, op. cit. pp. 135-142. Explicando este fenómeno, E. W. BOCKENFÖRDE escribe: "Tampoco se llegó a instaurar aquí [en los estados de Nueva Inglaterra] ese poder del Estado dotado de carácter soberano, y situado por encima de la tradición jurídica, que se fue imponiendo en Europa. En realidad esto no fue necesario, pues a diferencia de lo que ocurrió en la democracias burguesas de Europa, aqui no hubo que imponer ni ascgurar ningún tipo de reforma social y política contra la resistencia de los estratos hasta ese momento privilegiados, y tampoco tenían que hacer frente a las complicaciones que derivan de las relaciones exteriores con otros Estados" ("La democracia como principio constitucional", en Estudios sobre el Estado de Dercecho, cit., p. 120).
} 
acogida la idea que algún sujeto institucional pueda estar dotado de competencias normativas ilimitadas"

\section{\$3. Separación de poderes y democracia}

Al contrario de lo que sucedió en Francia, los padres fundadores de la nueva república americana diseñaron un modelo de democracia que no dejó lugar a la centralidad parlamentaria. Frente al parlamento fueron levantados -con poderes equivalentes al fin de servir de "frenos y contrapesos"- un presidente y un sistema de tribunales tan poderosos que cada cual daría lugar a una nueva forma del gobierno y de control del parlamento: el presidencialismo y la judicial review. Esta negación de la supremacía parlamentaria se basa no sólo en la genérica actitud de los americanos frente a los nuevos poderes que se veían en la necesidad de constituir, o en el rechazo a la compleja soberanía del parlamento británico, sino también en el explícito temor a la "tiranía de las mayorías".

Aunque naturalmente el modelo original de democracia americana no es exactamente idéntico al que predomina hoy en los países desarrollados, si hay algo en que las valoraciones resultan coincidentes es el principio de respeto hacia las minorias. En efecto, tal como en Montesquieu, el sentimiento predominante en los redactores de la nueva Constitución era de recelo hacia un sistema que dejara abierta la puerta a lo que puede identificarse con el "gobierno de la chusma". Como lo recuerda Richard Crossman, el estado civilizado se concebía en el fondo como una oligarquia de propietarios, por lo que una suerte de democracia plena causaba espanto ${ }^{46}$. Esta vieja preocupación, que había identificado Aristóteles al evidenciar los vicios de las formas perfectas de gobierno, llevó a optar por el sistema republicano como alternativa frente a la democracia ${ }^{47}$. No se veía otra manera de evitar los problemas que producen el espiritu de partido y las facciones, y el peligro que para los derechos de la minoría supone la existencia de una mayoría ${ }^{18}$.

La opción por un parlamento controlado resulta entonces plenamente deliberada, y es en congruencia con ese fin que la asamblea se divide en dos cámaras (diferenciadas por los "diferente formas de elección y principios de acción"), que se rechaza el modelo tradicional de estado unitario para reemplazarlo por una federación (de modo que el número y el tamaño de los estados también se entienda como forma de garantizar ese equilibrio y libertad) y que se conceden enormes poderes al presidente de la república.

\footnotetext{
${ }^{45}$ RLBUFFA, Giorgio: Costituzione c costiturionalismi (Giappichelli, Torino, 1990), p. 66, cursivas en el original.

46 CROSSMAN, Richard: Biogrufia del Estado moderno ( $\mathrm{T}_{\mathrm{r}}$. J. Fernández, Fondo de Cultura Económica, $2^{\mathrm{a}}$. reimpr. de la $1^{\mathrm{a}}$ ed. en castellano, Madrid, 1981), p. 71.

17 Sobre este tema, fundamental resulta HAMIITON, The Fedenalist Papers X, ed. cit, pp.122-128.

${ }^{48}$ IIAMIITON, The Federulist Papers L1, ed, cit, p. 321-322.
} 
Está fuera de duda que los redactores de la Carta de Filadelfia leyeron a Montesquieu $^{49}$. No es accidental la coincidencia entre la fórmula en que suele abreviarse el pensamiento de este último -que el poder detenga (arrêt) al poder- y la que se puede utilizar para sistetizar el pensamiento de los primeros: Ambition must be made to counteract ambition ${ }^{50}$. No obstante la lectura que predominaría en Europa continental, la inteligencia del libro en América fue lo bastante heterodoxa como para recrear una técnica muy especial de control al parlamento como productor de legislación. Esto obliga a decir algo sobre el judicialismo y de la judicial review.

\section{\$4. Judicialismo y judicial review}

\section{a) Judicialismo americano versus antijudicialismo europeo}

El sistema americano de control de la legislación es imposible de entender sin una visión más amplia de lo que son los jueces para una sociedad como ésa, donde, al decir de Tocqueville, la autoridad y la ciencia de los juristas también podía servir como instrumento para moderar la tiranía de la mayoría ${ }^{51}$.

Hace poco tiempo un profesor estadounidense escribía que tradicionalmente en Europa el estudiante de Derecho debía decidir entre ser famoso o ser juez ${ }^{52}$. Y aunque esta frase lo resume casi todo, viene al caso citar, el siguiente párrafo, sacado de una de las mejores sintesis comparatísticas del civil law: "En el common law nosotros sabemos lo que es un juez. El es un héroe de la cultura, incluso algunas veces una especia de figura paterna. Varios de los grandes nombres del common law pertenecen a jueces: Coke, Mansfield, Marshall, Story, Holmes, Brandeis, Cardozo (...) Pero en el mundo del civil law, un juez es algo enteramente diferente. Él es un empleado civil, un funcionario. La imagen neta es la de un juez como operador de una máquina diseñada y construida por los legisladores. Su función es sólo mecánica. Los grandes nombres del civil law no pertenecen a los jueces (¿quién conoce el nombre de un juez del civil law?) sino a los legisladores (Justiniano, Napoleón) o a la doctrina [scholars] (Gaius, Irnerius, Bartolus, Mancini, Domat, Pothier, Savigny, y una multitud de juristas europeos y latinoamericanos del siglo diecinueve o veinte)"

\footnotetext{
49 Asi por ejemplo Madison (Publius): HAMILTON, The Federalist Papers, ed. cit., XLVII, p. 205-206, y LXXXVIII, p. 331.

${ }^{50}$ HAMILTON, Tiel deralist Papers, op. cit., LI, p. 319.

51 TOCQUEVILle: La Democracia en América, op. cit, Primera Parte, Cap. VIII, pp. 267-273.

STTTH, Richard: "El problema del alto tribunal no razonable: Una visión norteamericana de la jurisdicción europea", en Das tżsiones norteamericanas de La jurisdicción de la Untón Europea (Publicaciones de la Cátedra Jean Monnet, Universidad de Santiago de Compostela, Santiago de Compostela, 2000), p. 24.

53

MERRYMAN, John H.: The Cinil Law Tradition. An introduction to the Legal Systems of Western Etrope and Latin America (2 ed, Stanford University Press, Stanford, 1990), pp. 36-37. No deja de llamar la atención la sensibilidad de los ojos ajenos para ver lo propio. En este sentido, la obra de Merryman se ubica en la misma tradición de Tocqueville y de Montesquicu. Para las caracteristicas del aitil law, en contraste con el common law y especialmente en cuanto al sistema de fuentes del Derecho, resultan especialmente útiles los ya clásicos: DAVID, R: I grandi sistemi giurridici contemporanei (Les
}

52 
Este modo de ver la función judicial, y de colocarla dentro del sistema constitucional, permite entender mejor el instituto de la judicial review.

\section{b) Bases de la judicial review}

A diferencia de lo que aconteció en Francia, los padres de la Constitución Federal no propusieron una revolución para sustituir el orden jurídico precedente, como tampoco lo hizo un siglo antes el pensamiento liberal en Inglaterra (donde el common law llegó a ser celebrado como muestra del genio nacional) ${ }^{5+}$. Por otra parte, al no darse ni en las colonias ni en Inglaterra las peculiaridades propias de la aristocracia judicial del antiguo régimen, el cuerpo de jueces no se convirtió en blanco de la reforma revolucionaria. Muy por el contratio, siempre se entendió que la función judicial era la mejor garantía de la libertad y, a la inversa del paradigma francés, la extensión de ésta debía ser directamente proporcional con los poderes de aquella. Esto último lo resumió Alexis de Tocqueville con las siguientes palabras: "A medida que la libertad aumenta, el círculo de atribuciones de los tribunales va siempre ensanchándose ${ }^{\text {} 55}$. La función contralora del poder judicial frente al parlamento, que aparecía como una consecuencia casi natural del federalismo (y los diversos niveles de lagalidad que éste supone) y de la constitución escrita y rígida, no encontraría entonces la resistencia que habría de enfrentar por largo tiempo en Francia.

En este contexto, que desde luego se entronca con una larga tradición judicialista heredada de Inglaterra ${ }^{56}$, resultan naturales las expresiones de Hamilton recogidas en E/ Federalista: "la completa independencia de los tribunales de justicia es particularmente esencial en una Constitución limitada. Por una Constitución limitada, yo entiendo una en la cual se contengan ciertas excepciones específicas aplicables a la autoridad legislativa (...) Limitaciones de esta especie no pueden ser preservadas en la práctica de otra forma que a través de los tribunales de justicia, cuyo deber es declarar nulos todos los actos contrarios al tenor manifiesto de la

Grandes Systemes de droit contemporains; tr. del fr. R. Sacco et al, Cedam, Padova, 1994), pp, 27 ss., y ZWEIGERT;, K. y KOTZ, H.: Introdrzionc al Diritto Comparuto (Einfibiryng in dic Rechtsergleichung, tr. del al. B. Pozzo, Giuffrc, Milano, 1992), vol, I. pp, 93 y ss.; como también el recientemente premiado libro de GI.ENN, P.. I egul traditions of the marld (Oxford University Press, 2000), pp 116 y ss. Las diferencias al interior de la familia angloamericana han sido expuestas en ATTYAH, P.S. y SUMMIZRS, R. Form and Siblstance in Anglo-American Law. A compantive Study of Legal Reasaning, Legal Theory and Legal Institutions (Clarendon Press, Oxford, reimpr. de la $1^{2}$ ed. de 1987, 1991). Para estos autores la aproximación americana al Derecho viene a ser más cercana a las sustancia que a las formas, mientras que la visión inglesa es más formalista, centralizada y monolitica (p. 33 y también pp. 411-415).

MERRYMAN, John, op. cit., p. 21.

55 TOCQUEVII.LE: La Democnacia en América (1835), vol. I, Primera Parte, Cap. VHI, ed. cit, p.146.

GARCIA DE ENTERRIA, Fduardo: La lengua... cit., pp. 147 y ss., y especialmente, Antonio C.: El ejempla.., cit., pp. 249 y ss. 
Constitución. Sin esto, valdrían para nada todas las reservas de los derechos o privilegios de los particulares"

Esta forma de entender la función judicial no implicaba elevar al poder judicial por sobre el poder legislativo, puesto que más importante parecía que los mandatarios se mantuvieran por debajo del mandato de servicio que se les había impuesto: "Alguna perplejidad han generado los derechos de los tribunales para anular actos legislativos contrarios a la Constitución, de la imaginación que esta doctrina implica una superioridad del judicial sobre el poder legislativo. Se argumenta que la autoridad de quien puede declarar nulos los actos de otra necesariamente debe ser superior a aquella cuyos actos puede anular" ${ }^{38}$, y sin embargo "no hay posición más clara que aquella que dice que todo acto de la autoridad delegada, contrario al tenor de la comisión bajo la cual es ejercida, es nulo. En consecuencia, ningún acto legislativo contrario a la Constitución puede ser válido. Negar esto sería afirmar que el sirviente se encuentra más arriba que su amo" 59 .

$\mathrm{Si}$ se examinan los argumentos que los antifederalistas difundieron para responder a los promotores de la nueva constitución, llama la atención el hecho de que, por sobre el argumento de la separación de poderes (que en cambio si fue utilizado con frecuencia para criticar la radicación de atribuciones judiciales en el Senado) ${ }^{60}$, pesó más la crítica al excesivo poder que irrogaba la facultad de anular la legislación, o la inexistencia de un control todavía superior (el viejo problema del quis custodes custodet) y de un único parámetro objetivo para resolver las controversias (al incluir la Constitución la equity como criterio para el ejercicio de la jurisdicción) o la posibilidad de que la Corte federal inclinara la balanza en favor de la federación y en perjuicio de los estados ${ }^{61}$.

En síntesis, en la visión que terminó por predominat, la posibilidad de que los jueces declarasen nulas las leyes contrarias la Constitución, y que por tanto se erigieran en baluartes [bulwarkes] de la Constitución ${ }^{62}$, no significaba afirmar que el poder de los jueces fuera superior al del parlamento, sino sólo asumir que "el poder del pueblo es superior a ambos" ${ }^{36}$. De este ideal sólo pasarían quince años para apreciar su valor en la realidad: en el año 1803 se dictó una de las sentencias más famosas de la historia constitucional moderna: Marbury v. Madison, donde por primera vez se aplicaron las teorías del Federalista declarándose que "una ley de la

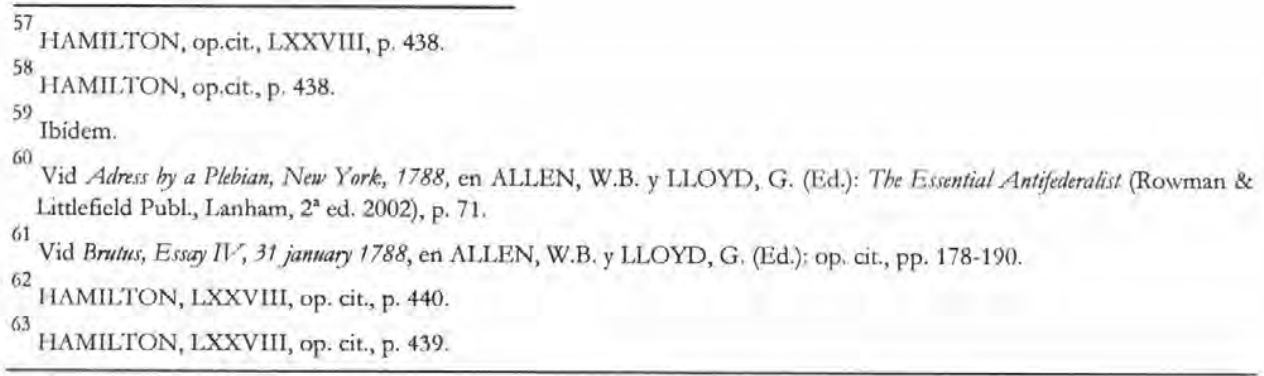


legislatura, incompatible con la Constitución es nula". Y aunque es cierto que la judicial revien se ha aplicado pocas veces en la historia de los Estados Unidos ${ }^{64}$, no cabe duda que es una característica del modelo sin la cual éste deja de ser reconocible.

\section{\$5. Constitución y Bill of Rights}

Se ha llamado muchas veces la atención sobre la diversidad cultural subyacente a ambas revoluciones y al impacto que éstas provocaron en la historia de la humanidad. La revolución americana fue tan exitosa como sobria, la francesa en cambio fue más espectacular, más dramática y por lo mismo más simbólica para la humanidad. De la revolución americana nadie se refirió como "bautizo de la humanidad", "alianza entre Dios y su pueblo" o "nueva hora de la creación", como en cambio se hizo repetidamente con la revolución francesa ${ }^{65}$. Esto explica que Emil Boutmy, en la conocida polémica con Jellinek acerca del origen de los derechos del hombre, destacara precisamente el carácter filosófico-pedagógico de la Declaración de 1789, que la convirtió en una especie de mensaje hacia la humanidad. Esa retórica, tan rica en abstracción como ineficacia, estuvo ausente en el discurso de los constituyentes americanos, para quienes los derechos tendrían inmediatamente un sentido jurídico. Con todo, lo que ahora interesa recordar es un hecho anterior a la aprobación del Bill of Rights, y que ilustra tanto o mejor las diferencias conceptuales entre uno y otro proceso revolucionario. Como se sabe, los miembros de la Convención omitieron deliberadamente la inclusión en la Constitución de un Bill of Rights al modo de los que ya habian sido redactados por las mismas colonias (v. gr, la Declaración de Derechos del Pueblo de Virginia, 1776) y de los que estaba por redactarse en el continente europeo. Como se advertirá, las razones que explicaron la omisión original no sólo son útiles para ilustrar el pensamiento de los padres fundadores sino que además pueden servir para reflexionar sobre un fenómeno contemporáneo: la inflación de derechos nuevos.

Respondiendo a la crítica de los antifederalistas ${ }^{66}$, Alexander Hamilton explicaba la deliberada omisión del siguiente modo: “La más considerable de las

\footnotetext{
64

Esta atribución no seria nuevamente utilizada sino hasta el polémico fallo Dred Scalt de 1857, lo que "ha permitido a la doctrina subrayar el hecho de que, en gran medida, el control judicial de las leyes federales se consolido en Norteamérica en gran medida debido a su no ejercicio práctico" (BLANCO, Roberto: op. cit., p. 185-186).

65

HABERLE, Peter: Libertad, ignaldad y fruternidad. 1789 como bistoria, actralidad y futum det Estado constitucional ( $\mathrm{I}_{\mathrm{r}} \mathrm{I}$. Gutiérres, Trotta, Madrid, 1998), p. 33-34, citando la literatura contempóranea a la revolución.

${ }^{66}$ Vid. "The dissent of the minority of the Convention of Pennsylvania", 18 diciembre de 1787, en ALLEN, W.B. $y$ LI.OYD, G. (Ed.): The Essentual Antifederalist (Rowman \& Littlefield Publ., Lanham, $2^{2}$ ed. 2002), eit., p. 41. Para una compresión más profunda, vid.: DRY, Murray: "The Case Against Ratification: Anti-Federalist Constitutional Thought", en LEVY, Leonard y MAHONEY, Dennis: The Framing and Ratification of the Constitution (Mac Millan Publ., New York, 1987), pp. 271-291 y, especialmente, RUMBLE, Wilfrid: "James Madison on the Value of bills of Rights", en PENNOCK, J, Roland y CHAPMAN, John (Eds.): Canstitutionalism. Nomos XX (New York University Press, N. York, 1979), pp. 122-162.
} 
críticas que me falta por responder es que el plan de la Constitución no contiene una declaración de derechos [bill of rights] (...) Es entonces evidente que de acuerdo a su primitiva significación, las declaraciones no tiene aplicación en constituciones expresamente fundadas en el poder del pueblo (...) Estrictamente el pueblo nada abandona, y como lo retiene todo no tiene necesidad de provisiones particulares" A este argumento, esencialmente liberal, agregaba: "Voy más lejos y afirmo que las declaraciones de derechos, en el sentido y con el alcance con el cual se pretenden, no sólo son innecesarias en la Constitución propuesta, sino que incluso podrían llegar a ser peligrosas. Ellas contendrían varias excepciones a poderes que no han sido concedidos; $y$, en lo que importa, proporcionarían un pretexto para reclamar más poderes de los que han sido concedidos. ¿Para qué declarar que ciertas cosas no se podrán hacer, si no bay poder para hacerlas?"68.

Aunque esta omisión duró poco tiempo (hasta las diez primeras enmiendas de 1791), el razonamiento de fondo permite otro contraste con el curso seguido en Francia tras la revolución, donde la Declaración de Derechos de 1789 no sólo precedió la primera constitución republicana sino que también fue modificada por varias de las constituciones que siguieron a la de $1791^{69}$. El razonamiento de Hamilton escondía un principio protector bastante claro: que el silencio de la ley, en materia de derechos fundamentales, no implica necesariamente una laguna en perjuicio de la libertad, sino más bien en su favor. Hoy día la complejidad que ha asumido la función social de los derechos fundamentales (éstos ya no sólo imponen deberes de omitir sino también programas y obligaciones de hacer ${ }^{70}$ pudiera llevar a pensar que el argumento de Hamilton es sólo historia superada por las necesidades del presente. Sin embargo, desde que toda codificación de derechos es por sí misma imperfecta, ello no es así. Delante del hábito febril que, con tanta buena voluntad como poca reflexión, lleva a reformar con frecuencia las

\footnotetext{
67

HAMILTON, op.cit, LXXXIV, p. 473-475.

68

, 476 (cursivas agregadas)

Asi, las declaraciones de 1793, 1795 y 1848 . El texto de estas declaraciones, como asimismo de los variados proyectos que antecedieron a la famosa Déclaration de 1789 puede consultarse en la valiosa recopilación de Christine FAURÉ: Las deckaraciones de los derechos del bombre de 1789 (Tr. D. Sánchez y J. Nủnez, Fondo de Cultura Económica, México, 1995).

Cf. BOCKENFORDE, Ernst: "Teoría e interpretación de los derechos fundamentales", en Escritos sobre Dereches Fundamentales (Tr. J. Requejo e I. Villaverde, Nomos Verlag., Baden Baden, 1993), pp. 44 y ss. Por otra parte, inclusa en su dimensión negativa más radical, la disciplina de los derechos requiere las más de las veces de la intervención del legislador. Los derechos codificados, en este último caso, cumplen tanto una función declarativa como restrictiva del poder normativo del Parlamento. Desde luego, en la perspectiva que hemos presentado, es esta segunda función la que parece más relevante.
} 
constituciones para mantenerlas "ajustadas al compás de los tiempos" (especialmente a través de la incorporación de los "nuevos derechos") el razonamiento de Hamilton sirve como la compresa que puede bajar la fiebre; el detalle radica, claro está, en que el enfermo esté dispuesto a usarla. 